Results In total 1012 BAME people were engaged with; 804 completed questionnaires and 208 took part in 11 focus groups.

Conclusions Whilst it was true that there were religious and cultural barriers preventing local BAME communities accessing our services, what proved more prolific was the lack of awareness of the actual services provided. This research contains a wealth of knowledge about the religious needs of the communities engaged with, and suggestions from the actual communities about how they can be met. They acknowledged how we are already meeting their needs in some respects but highlighted that there were some barriers that simply could not be overcome. The key recommendation was the creation of a Steering Group to act as an advisory panel on strategy that guides through the development of culturally accessible service provision and facilitate ongoing relationships and engagement with BAME communities.

\section{P-46 'TELL US THERE IS NO CURE'- BAME COMMUNITIES SEEK CLEAR COMMUNICATION TO PREPARE FOR DYING}

Tricia Wilcocks, Joanne Leung. ellenor Gravesend, Kent, UK

\subsection{6/bmjspcare-2017-hospice.73}

Background Black, Asian and Minority Ethnic (BAME) groups have less access to palliative care due to deficient knowledge and awareness, culturally inappropriate services, communication barriers and more (Evans et al., 2011; Koffman, 2014; Calanzani et al., 2013; Smith et al., 2015). To support person-centred care (The Health Foundation, 2014) and to exchange skills and knowledge, a group of palliative care providers, charities and voluntary organisations, minority ethnic groups and academic researchers formed a Learning Alliance (LA). The LA attained funding from Health Education England to organise a consultation event with BAME groups and healthcare service providers, in order to examine and improve the existing palliative care services.

Aims Enhancing awareness of palliative care services. Improve understanding of how to engage with BAME groups at end of life.

Methods The consultation event introduced palliative care services to BAME groups, followed by group discussions exploring barriers of assessing the service, challenges in coping in the last year of life for a family member and understanding how best to communicate with local communities. The discussion summary was then relayed to healthcare service providers to improve service development for BAME communities.

Results 82 people attended, including representatives from religious and faith groups, carer support and commissioning groups. BAME communities gave some clear messages:

- 'Tell us there is no cure, so we can work on life we have left and prepare for death.'

- Use every means possible, radio, social media, events and posters, to continuously promote awareness.

- Use of confusing or misleading language to avoid the pain and reality of dying denies the opportunity to prepare for death.

Conclusion Service providers should utilise a wide range of media to explain available healthcare services but communication about end of life and palliative care needs to be simplified for minority groups. The LA was compelled to facilitate further outreach work with ethnic groups, to improve the quality of care and address unmet needs.

\section{P-47 A LEARNING ALLIANCE: EXPLORING PALLIATIVE CARE ISSUES AMONG ETHNIC GROUPS IN SOUTH EAST ENGLAND}

Joanne Leung. ellenor Gravesend, Kent, UK

10.1136/bmjspcare-2017-hospice.74

Background National Census (2011) (Office for National Statistics, 2012) indicated that the South East region had 9.3\% of non-white ethnic groups; yet, these groups had lower access, usage and satisfaction rates to palliative care services compared to people of White ethnicity (Calanzani et al., 2013; Dixon et al., 2015). In order to cater for the various needs of the local service users in a sustainable manner, a Learning Alliance (LA) was formed in South East England. This LA was comprised of palliative care providers, charities and voluntary organisations, minority ethnic groups and academic researchers, with funding for events provided by the local Health Education England network.

Aims By working collaboratively across the LA, it is anticipated that the emerging supportive and palliative care needs from the local population will be identified, mapped and addressed.

Methods The LA would organise two consultation events, which were designed for the Black, Asian, Eastern European, Romany and Traveller ethnic groups, to explore issues in providing and accessing palliative and end of life care services. The summary of these consultations was conveyed to healthcare service providers and expected to lead to potential research projects.

Results The LA has built a consolidated and viable network to support the healthcare service providers and users to enhance the uptake of the palliative care services, as well as to share expertise and practices with one another. Its consultation events and potential future research projects help the stakeholders to recognise the shortfalls of the existing services in order to rectify the inequalities within the healthcare services. Conclusion Reaching out and working alongside the health care service providers and minority ethnic groups allow both parties to increase awareness of the diversity needs and the suitability of the palliative care services. In the long term, the LA will be attempting to transfer and apply its findings to the wider minority population groups.

\section{P-48 THE DISADVANTAGED DYING: EXPLORING THE END OF LIFE PRIORITIES OF HOMELESS ADULTS IN THE UK}

Wendy Ann Webb, Theresa Mitchell, Brian Nyatanga, Paul Snelling. University of Worcester, UK

\subsection{6/bmjspcare-2017-hospice.75}

Background With limited resources and no stable accommodation, people who are homeless arguably have greater need of palliative care support than the rest of society when they face the end of life. However, they consistently fail to access palliative care services (Care Quality Commission, 2016) and while there is much in the literature surrounding the barriers to appropriate health care (Hudson et al., 2016), their specific 